\title{
Is it meaningful to distinguish between Facebook addiction and social networking sites addiction? Psychometric analysis of Facebook addiction and social networking sites addiction scales
}

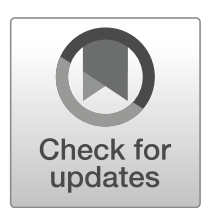

\author{
Julia M. Balcerowska ${ }^{1}$ (D) Piotr Bereznowski ${ }^{1}$ - Adriana Biernatowska ${ }^{1} \cdot$ Paweł A. Atroszko $^{1} \cdot$ Ståle Pallesen $^{2}$. \\ Cecilie Schou Andreassen ${ }^{3,4}$
}

Published online: 28 January 2020

(C) The Author(s) 2020

\begin{abstract}
Studies conducted on Social Networking Sites (SNSs) addiction have to a large extent focused on Facebook as a prototypical example of SNS. Nonetheless, the evolution of SNSs has spawn conceptual and methodological controversies in terms of the operationalization of SNS addiction. In order to bring more clarity to this field the present study aimed to investigate the construct validity of the Bergen Social Media Addiction Scale (BSMAS) in comparison to the Bergen Facebook Addiction Scale (BFAS) among 1099 young subjects (146 Facebook-only users and 953 who had an account on Facebook and at least one additional SNS). Furthermore, the study aimed to investigate the unique contribution of SNS addiction to stress and general well-being above and beyond personality characteristic and Facebook addiction specifically. Participants completed a survey assessing SNS addiction, Facebook addiction, demography, Big Five personality traits, perceived stress, and general subjective well-being. BSMAS had acceptable fit with the data and demonstrated good reliability. Results showed that the scores of BSMAS were strongly associated with those of BFAS and that the relationship between the two measures was stronger in the group of Facebook-only users than in the group of multisite-social networkers. Moreover, SNS addiction was positively associated with perceived stress and negatively associated with subjective well-being after controlling for Facebook addiction and other study variables. Theoretical and methodological implications of the findings are discussed.
\end{abstract}

Keywords SNS addiction $\cdot$ Facebook addiction $\cdot$ Scale $\cdot$ Personality $\cdot$ Well-being $\cdot$ Stress

\section{Introduction}

Social Networking Sites (SNSs) are "virtual communities where users can create individual public profiles, interact with real-life friends, and meet other people based on shared interests" (Kuss and Griffiths 2011 p. 3529). Social networking is currently one of the most popular forms of communication and entertainment among Internet users (GlobalWebIndex 2018). It is estimated, that in 2021, there will be approximately 3 billion SNSs users globally (Statista 2019). However, there is growing scientific evidence suggesting that excessive use of social networking sites may result in symptoms traditionally associated
Julia M. Balcerowska

julia.balcerowska@phdstud.ug.edu.pl

Piotr Bereznowski

piotr.bereznowski@phdstud.ug.edu.pl

Adriana Biernatowska

biernatowskaa@gmail.com

Paweł A. Atroszko

p.atroszko@ug.edu.pl

Ståle Pallesen

Staale.Pallesen@uib.no
Cecilie Schou Andreassen

Cecilie.Andreassen@uib.no

1 Faculty of Social Sciences, Institute of Psychology, University of Gdańsk, Bażyńskiego 4, 80-309 Gdańsk, Poland

2 Department of Psychosocial Science, University of Bergen, Christiesgate 12, Postboks 7807, 5020 Bergen, Norway

3 Department of Social Studies, University of Stavanger, Stavanger, Norway

4 Department of Clinical Psychology, University of Bergen, Christiesgate 12, Postboks 7807, 5020 Bergen, Norway 
with substance-related addictions (Andreassen 2015; Grant et al. 2010; Griffiths et al. 2014; He et al. 2017).

\section{SNS Addiction as an Example of Behavioral Addiction}

SNS addiction is by some scholars regarded as a behavioral addiction, emerging from the framework, theoretical work and research on Internet addiction (Andreassen et al. 2016; Kuss and Griffiths 2011; Montag et al. 2014; Müller et al. 2016; van Rooij et al. 2017; Young 2009). It has been defined as "being overly concerned about SNSs, driven by a strong motivation to $\log$ on to or use SNSs, and to devote so much time and effort to SNSs that it impairs other social activities, studies/job, interpersonal relationships, and/or psychological health and well-being" (Andreassen and Pallesen 2014 p. 4054). According to the components model of addictions (Griffiths 2005), the symptoms of SNS addiction include salience, mood modification, tolerance, withdrawal, relapse, and conflict. Previous empirical findings suggest that SNS addiction may be a serious mental health problem with negative consequences for the psychosocial functioning of the sufferer and next of kin (see Andreassen 2015). Although there has been a rise in the number of studies on SNSs use and abuse, the status of SNS addiction is still to be formally acknowledged.

\section{Conceptual and Methodological Perspectives on SNS Addiction}

In the fourth quarter of 2018, Facebook had involved on average 1.52 billion daily active users (Facebook 2019). As one of the biggest social networking websites, Facebook has become almost synonymous with social networking (Griffiths 2012). Studies conducted on SNS addiction have so far mainly focused on Facebook addiction, as Facebook was one of the first SNS established and has since been regarded as a prototypical example of SNS (see Marino et al. 2018a; Ryan et al. 2014). However, with the variety of apps and services that SNSs users have at their disposal today, social networking has become eclectic (Kuss and Griffiths 2017). Internet users can decide to maintain accounts across a wide range of platforms (e.g. Instagram, Snapchat, Twitter, Pinterest). In 2016 the average Internet user had accounts on almost eight different social websites (GlobalWebIndex 2017). Among those who have account on Facebook only, SNS addiction and Facebook addiction should be regarded as equivalent. On the other hand, SNS addiction and Facebook addiction does not necessarily reflect the same phenomenon among multisite-social networkers. Accordingly, SNS addiction and Facebook addiction should be viewed as similar but separate entities among multisite-social networkers (Kuss and Griffiths 2017).

Based on SNS addiction theory and empirical findings, the dynamic evolution of social networking sites has spawn controversies from both conceptual and methodological perspectives (see Andreassen and Pallesen 2013; Griffiths 2012). According to uses and gratifications theory, the use of a particular media is goal-directed and could be related to different forms of gratification as well as distinct needs underlying this use (Katz et al. 1973). From this perspective it seems crucial to take results from studies about specific sites into account in order to understand the development of SNS addiction (Ryan et al. 2014). In line with this, studies have now focused on addiction to specific platforms, for example Instagram (Kircaburun and Griffiths 2018), Twitter (Ndasauka et al. 2016) and Snapchat (Punyanunt-Carter et al. 2017). Contrarily, some scholars still suggest that SNS addiction should be framed as a behavior detached of a particular SNS platform and that addictions to specific sites are only examples of SNS addiction (Griffiths et al. 2014; Kuss and Griffiths 2017). According to the latter approach, SNS addiction is viewed as a generic phenomenon (e.g. Tang and Koh 2017; Wang et al. 2018). In line with such understanding, impairment associated with Facebook addiction (related for example to higher stress and lower well-being) should also be present in SNS addiction generally. Another theoretical viewpoint concerns which aspects of a particular site (e.g. Facebook) or SNS in general, are in fact addictive and cause mental problems (Andreassen and Pallesen 2013, 2014).

\section{Bergen Social Media Addiction Scale and Bergen Facebook Addiction Scale}

Along with the discussion about the nature of the phenomenon of SNS addiction, research efforts have been taken with the aim of developing scales to measure addiction to specific sites (e.g. Facebook Intrusion Questionnaire; Elphinston and Noller 2011; Facebook Dependence Questionaire; Wolniczak et al. 2013) as well as SNS addiction in general (e.g. Addictive Tendences Towards SNSs; Wu et al. 2013; Social Networking Website Addiction Scale; Turel and Serenko 2012). The Bergen Facebook Addiction Scale (BFAS; Andreassen et al. 2012) was constructed based on general addiction theory, and measures Facebook addiction according to six basic addiction symptoms (i.e. salience, conflict, mood modification, withdrawal, tolerance, and relapse; Griffiths 2005). The BFAS has been adapted into several languages and has overall demonstrated good psychometric properties (e.g. Atroszko et al. 2018; Phanasathit et al. 2015; Wang et al. 2015). Nonetheless, a limitation of the scale is that is assesses addiction to one specific platform (i.e. Facebook) only. In order to overcome this limitation, the Bergen Social Media Addiction 
Scale (BSMAS; Andreassen et al. 2016) was developed and represents a modified version of the BFAS replacing "Facebook" with "social networking sites", the latter being defined as "Facebook, Twitter, Instagram and the like" in the instructions. While the names "Bergen Social Media Addiction Scale" and "Bergen Social Networking Addiction Scale" are used interchangeably in the literature (Andreassen et al. 2017; Andreassen et al. 2017), we use in the following "social networking sites" as social media and social networking sites reflect similar but yet distinct phenomena (see Kuss and Griffiths 2017). The psychometric robustness of the BSMAS has been examined in Italian (Monacis et al. 2017), Hungarian (Bányai et al. 2017), Persian (Lin et al. 2017), and Chinese (Leung et al. 2020; Chen et al. 2020) samples, where it has showed good properties. Although previous studies have used a variety of methods to examine this scale, there is currently no study that has investigated the psychometric properties of the BSMAS in comparison to the BFAS. What is more, there is currently no empirical study that has investigated the relationship between a specific and a generic SNS addiction scale.

\section{SNS Addiction, Personality and Well-Being}

Theoretical models of problematic Internet use and SNS addiction have emphasized the prominence of predisposing factors (Andreassen 2015; Atroszko et al. 2018; Brand et al. 2014; Caplan 2010; Davis 2001; Pelling and White 2009). Studies on SNS addiction have in this realm emphasized the role of certain personality traits predicting both use and abuse of SNS (Andreassen et al. 2013). With reference to the Big Five (Extraversion - being outgoing, talkative; Agreeableness - being sympathetic and warm; Conscientiousness - being organized and prompt, Neuroticism - being nervous and moody; Openness/Intellect- being creative and intellectually oriented) model of personality (Wiggins 1996) general SNS addiction and Facebook addiction have quite consistently been positively related to neuroticism (De Cock et al. 2014; Marino et al. 2018a) and negatively to conscientiousness (Błachnio et al. 2017; De Cock et al. 2014; Marino et al. 2018a). What is more, a metaanalysis showed a weak negative relationship between extraversion, agreeableness and openness to experience and Facebook addiction (Marino et al. 2018a). In terms of mental health both Facebook addiction and more general SNS addiction have been found to be associated with low well-being and psychological distress (Atroszko et al. 2018; Hou et al. 2017; Marino et al. 2018b; Pontes 2017). Hormes et al. (2014) reported that Facebook addiction is related to emotional regulation deficits and susceptibility to both substance and non-substance addiction. Addictive use of WeChat has been found to be negatively associated with users' physical, mental and social health beyond personality traits and demographic variables (Xue et al. 2018). Previous studies have also suggest that both typical and excessive SNS users experience reduction in perceived stress and improvement in well-being following SNS abstinence of several days. Furthermore, the positive effects were more substantial in the excessive SNS user group than among typical SNS users (Tromholt 2016; Turel et al. 2018). These findings suggest that both general and specific SNS-addiction seems to have parallel relationships with well-being and mental health. However, in the context of the constantly changing nature of SNSs, it is crucial to investigate the relative contribution of those phenomena in terms of well-being and mental health among different SNSs users. Taking into account that SNS addiction as a generic form of addiction might cumulate addictive properties from different SNSs it should also impair the well-being above and beyond addiction of (e.g. Facebook) specific sites.

\section{Aims of the Present Study}

In the light of abovementioned theoretical and methodological discussion about SNS addiction, the aim of the present study was to investigate the validity and reliability of the BSMAS among social networking sites users. Among Facebook-only users and multisite-social networkers, SNS addiction and Facebook addiction do not necessarily reflect the same phenomenon. The present study aimed accordingly to compare the strength of the relationship between Facebook addiction and SNS addiction among Facebookonly users and multisite-social networkers, respectively. Previously, no study has investigated the psychometric properties of the BSMAS in comparison to the BFAS. Therefore, the present study is the first to compare the psychometric properties of the BSMAS in comparison to the BFAS in a sample of different SNSs users. In line with this, the present study is the first where a specific and a generic SNS addiction scale are compared. Previous empirical findings suggest that SNS addiction is related to specific personality risk factors and impairment of well-being and mental health. Accordingly, the aim of the present study was to examine the relationships between SNS addiction, personality traits, perceived stress and general subjective well-being. Last but not least, SNS addiction as a generic form might reflect addictive behavior in relation to several SNSs and is therefore expected to impair well-being and increase stress above and beyond addiction of (e.g. Facebook) specific sites. Consequently, the study aimed to identify the unique contribution of SNS addiction to stress and well-being beyond personality characteristics and Facebook addiction among multisite-social networkers.

\section{Hypotheses}

On the basis of previous research and theoretical frameworks, it was hypothesized that (i) the Bergen Social Media Addiction Scale has good validity and reliability, 
and a single factor solution in a Polish sample (H1); (ii) the scores of the BSMAS and the BFMAS will correlate highly, although the relationship between the scores will be stronger in the group of Facebook-only users than in a group of multisite-social networkers (H2); (iii) emotional stability and conscientiousness are inversely related to SNS addiction (H3); (iv) SNS addiction is positively related to stress and inversely related to well-being (H4); (v) the relationships between Facebook addiction and criterion variables (gender, age, personality, stress and well-being) are the same as the relationships between SNS addiction and criterion variables in group of multisite-social networkers (H5); (vi) SNS addiction explains significantly proportions of variances in stress and well-being above and beyond age, gender, personality traits and Facebook addiction among multisite-social networkers (H6).

\section{Methods}

\section{Sample}

Initially, the sample comprised 1183 respondents. Before the analyses, data was screened and data from three participants who did not have accounts on any social networking sites were excluded. Due to missing data on relevant variables, 81 participants were further eliminated from the analyses. Thus, the final sample comprised 1099 participants. The sample was divided into two groups based on the number of accounts on social networks. Figure 1 presents the distribution of the number of accounts on social networking sites. There were 146 (13.3\%) subjects who only had Facebook account (Facebook-only users) whereas $953(86.7 \%)$ had accounts on Facebook and at least one additional SNS (multisite-social networkers). Multisite-social networker individuals reported using an average of 3.51 different SNS $(S D=1.30)$. In addition to Facebook, $738(77.4 \%)$ of them had an Instagram account and $697(73.1 \%)$ had a Snapchat account. The sample was diverse in terms of sociodemographic features (see Table 1).

\section{Instruments}

Social Networking Sites Addiction The Bergen Social Media Addiction Scale (BSMAS) is a modified version of the Bergen Facebook Addiction Scale (Andreassen et al. 2012). The modification involves replacing the word "Facebook" with "social networking sites" the latter being defined as "Facebook, Twitter, Instagram and the like" in the instructions to participants (Andreassen et al. 2016). The Polish version of the scale was administered. The responses are provided on a 5-point Likert scale ranging from very rarely (1) to very often (5). The BSMAS has shown good validity and reliability in previous research (Andreassen et al. 2016; Andreassen et al. 2017; Bányai et al. 2017; Lin et al. 2017; Monacis et al. 2017). The scale has shown measurement invariance across two Chinese cultural areas (Leung et al. 2020), as well as time invariance (Chen et al. 2020). In the present study the Cronbach's alpha reliability coefficient was .77 . The Appendix provides a full list of the items in the Polish and English versions of the scale, respectively.

Facebook Addiction The Bergen Facebook Addiction Scale (BFAS; Andreassen et al. 2012) includes six items that are based on the addiction components model (Griffiths 2005). Responses are provided on a 5-point Likert scale ranging from very rarely (1) to very often (5). The Polish version of the BFAS has shown good validity and reliability in previous studies (Atroszko et al. 2018; Charzyńska and Góźdź 2014). The scale has also shown good psychometric properties when adapted into other languages (Phanasathit et al. 2015; Pontes et al. 2016; Silva et al. 2018; Wang et al. 2015). In the present study the Cronbach's alpha reliability coefficient of the BFAS was .81 .
Fig. 1 Percentage distribution of the number of accounts on social networking sites

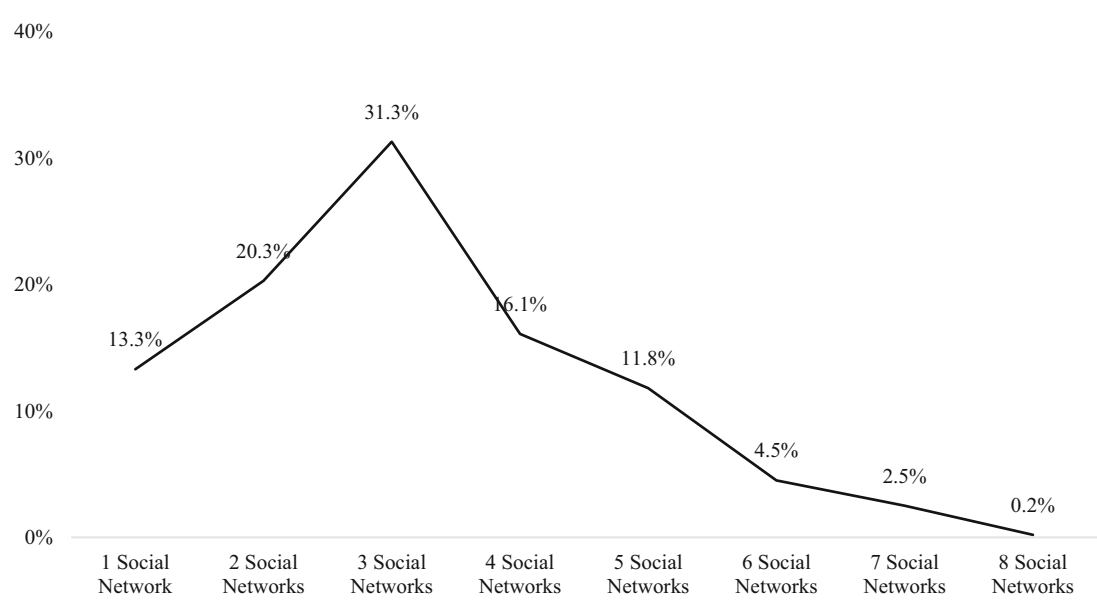


Table 1 Descriptive statistics of sociodemographic features in the sample

\begin{tabular}{|c|c|c|c|c|c|c|}
\hline & \multicolumn{2}{|l|}{ Total } & \multicolumn{2}{|c|}{ Facebook-only users } & \multicolumn{2}{|c|}{ Multisite-social networkers } \\
\hline & Frequencies $(f)$ & Percentages/ Mean (SD) & Frequencies $(f)$ & Percentages/ Mean (SD) & Frequencies $(f)$ & Percentages/ Mean (SD) \\
\hline Females & 790 & $71.9 \%$ & 83 & $56.8 \%$ & 707 & $74.2 \%$ \\
\hline Males & 309 & $28.1 \%$ & 63 & $43.2 \%$ & 246 & $25.8 \%$ \\
\hline Age & & $21.44(2.85)$ & & $21.25(2.41)$ & & $22.69(4.64)$ \\
\hline Studying & 1037 & $94.4 \%$ & 136 & $93.2 \%$ & 901 & $94.5 \%$ \\
\hline Working students & 364 & $35.1 \%$ & 48 & $32.9 \%$ & 316 & $33.2 \%$ \\
\hline Working & 51 & $4.6 \%$ & 9 & $6.2 \%$ & 42 & $4.4 \%$ \\
\hline Unemployed & 11 & $1.0 \%$ & 1 & $0.07 \%$ & 10 & $1.0 \%$ \\
\hline
\end{tabular}

Personality The Polish version (Atroszko 2015) of Ten Item Personality Inventory (TIPI; Gosling et al. 2003) was used to assess the five-factor model of personality: Extraversion, Agreeableness, Conscientiousness, Emotional stability, and Openness to experience. Respondents provided answers on a 7-point Likert scale, ranging from disagree strongly (1) to agree strongly (7). The TIPI has shown good validity and reliability in previous studies (Atroszko 2015; Atroszko et al. 2016a, 2016b; Atroszko et al. 2018). In the present study the Spearman-Brown reliability coefficient was of .74 for Extraversion, .29 for Agreeableness, .72 for Conscientiousness, .62 for Emotional stability and .35 for Openness, respectively. The TIPI demonstrates good validity, still biased estimates of reliability using internal consistency measures which is expected due to the small number (just two) of items per dimension (Gosling et al. 2003). Therefore, less biased measures of reliability should be used, such as the test-retest reliability, which for the original scale yielded acceptable correlations between repeated measurements with 6-week interval, varying from .62 for Openness to .77 for Extroversion (Gosling et al. 2003).

Stress Perceived stress was measured by the Polish short version of Perceived Stress Scale (PSS-4; Cohen et al. 1983). It consists of four items with a 5-point Likert response format scale, ranging from never (1) to very often (5). The scale has shown good validity and reliability in previous research (Atroszko 2015; Atroszko et al. 2015; Atroszko et al. 2018). The Cronbach's alpha reliability coefficient was .75 in the present study.

Subjective Well-Being The Polish version of the Ultra-Short Protocol for Measuring Subjective Well-Being (USPSWB) was used to assess general subjective well-being. It consists of six items based on the WHOQOL-BREF (Skevington et al. 2004). The scale covers three (out of four) main domains distinguished by the WHO: physical (general health, sleep quality), psychological (satisfaction with life, meaning in life) and social (satisfaction with personal relationship, satisfaction with support received from friends). The responses are provided on a 9-point Likert scale ranging from (1) not at all to (9) an extreme amount in case of items regarding satisfaction with life and meaning in life. The response alternatives for the other items range from (1) very dissatisfied to (9) very satisfied. The scale has shown good validity and reliability in previous research (Atroszko et al. 2019). As this is a fairly new measure and since papers describing its psychometric properties have not been published yet, we decided to report the results of its structure using confirmatory factor analysis: The model with three first-order factors (physical, psychological, and social) and one second-order factor (general subjective well-being) showed good fit with the data: $\chi^{2}(6)=4.68, \chi^{2} / d f=0.78, \mathrm{CFI}=1.000, \mathrm{TLI}=1.001$, RMSEA $=.000,90 \%$ CI [.000-.034]. In the present study, the Cronbach's alpha reliability coefficient of general subjective well-being was .75 .

\section{Procedure}

Data were collected through both pen-and-pencil and an online questionnaire. Students from Polish universities: the University of Gdańsk, the Polish Naval Academy and the Gdańsk University of Technology were invited to participate anonymously during lectures or classes. The estimated response rate was above $95 \%$. The online survey was conducted via a questionnaire placed on Facebook. Respondents were asked to click on a link to access the survey. The response rate for online surveys is impossible to determine (Fan and Yan 2010). Before starting to respond, the participants received detailed information about the study. Data collection occurred from November 2017 to March 2018. The final sample included $57.1 \%$ participants recruited via paper-and pencil survey and $42.9 \%$ via online survey. Participation was completely anonymous and no monetary or other material rewards were offered. 


\section{Statistical Analyses}

Confirmatory factor analysis (CFA) was performed to assess the construct validity of the BSMAS where a 6-item one-factor solution was tested. In order to investigate the validity of the BSMAS and the BFAS and to explore if SNS addiction and Facebook addiction do reflect the same phenomenon, a model with two latent variables (SNS addiction and Facebook addiction) was investigated where items corresponding to the same criteria were correlated. To indicate the differences between Facebook-only users and multisite-social networkers, the model was also investigated in the two samples. Robust Weighted Least Squares (WLSMV) estimator was used. The following measures were used to evaluate model fit: $\chi^{2}$ divided by degrees of freedom $\left(\chi^{2} / d f\right)$, the Comparative Fit Index (CFI), the Tucker-Lewis Index (TLI) and the Root Mean Squared Error of Approximation (RMSEA). Cut-off scores for those indexes in terms of acceptable fit are: $\chi^{2} / d f \leq 3$, $\mathrm{CFI} \geq 0.95$, TLI $\geq 0.95$, RMSEA $\leq 0.06$ to 0.08 (Hu and Bentler 1999; Schreiber et al. 2006). Mplus 6.11 (Muthén and Muthén 1998-2010) was used to perform the CFA.

Means, standard deviations, percentages, and correlation coefficients were calculated for the entire sample. In the group of multisite-social networkers the correlations between SNS addiction and criteria variables were compared to correlations between Facebook addiction and the same variables. By comparing the correlations, it was possible to investigate whether the BSMAS and BFAS criterion validity was different. Two hierarchical regression analyses were conducted for the multisite-social networkers group where stress and subjective well-being comprised the dependent variables. An overview of the independent variables introduced in the subsequent steps can be found in Table 4. The proposed model allowed testing whether SNS addiction, regardless of other variables, is a source of decreased well-being and increased stress. For all linear regression analyses, preliminary analyses were conducted to ensure no violation of the assumptions of normality, linearity, multicollinearity, and homoscedasticity. To compare latent correlation coefficients between Facebook addiction and SNS addiction between the groups of Facebook-only users and multisite-social networkers a $z$ test for independent groups was used. Furthermore, a $z$ test for dependent groups was used to compare correlation coefficients between Facebook addiction and criterion variables and correlations between SNS addiction and the same criterial variables within the group of multisite-social networkers. All tests were twotailed, and the alpha level was set to .05 .

\section{Ethics}

The study was carried out in accordance with the Declaration of Helsinki. All gathered data was anonymous, and participants were informed about all the proper details about the study and their role in it, including that they could withdraw at any point. Attaining formal and written informed consent was not regarded as necessary as voluntary completion of the questionnaires was regarded as providing consent, the study was anonymous and since no medical information was gathered.

\section{Results}

The model with one factor of SNS addiction showed the following fit indices: $\chi^{2}(9)=251.64, \chi^{2} / d f=27.96, \mathrm{CFI}=.924$, $\mathrm{TLI}=.874, \mathrm{RMSEA}=.157,90 \%$ CI $[.140-.174]$. Standardized factor loadings of the items were: $.66, .84, .66$, $.50, .73, .60$, respectively. Due to lack of acceptable model fit, residuals of the first and second items were allowed to correlate on the basis of modification indices, similarly to previous studies concerning the BFAS (Atroszko et al. 2018; Charzyńska and Góźdź 2014) and the BSMAS (Monacis et al. 2017). Additionally, residuals of the fourth and sixth items were correlated on the basis of modification indices. The modified model had an acceptable fit: $\chi^{2}(7)=47.57, \chi^{2} /$ $d f=6.80, \mathrm{CFI}=.987, \mathrm{TLI}=.973, \mathrm{RMSEA}=.073,90 \% \mathrm{CI}$ $[.054, .093]$. Standardized factor loadings on items were: $.48, .72, .71, .49, .80, .59$, respectively. The correlation between residuals of the first and second item was .50 , while the correlation between residuals of the fourth and sixth item was .23 .

The model with two latent variables (Facebook addiction and Social Networking Sites addiction) and items corresponding to the same criteria correlated did not have an acceptable model fit in the group of Facebook-only users: $\chi^{2}(47)=$ $211.06, \chi^{2} / d f=4.49, \mathrm{CFI}=.916, \mathrm{TLI}=.882$, RMSEA $=.155,90 \%$ CI $[.134, .176]$ and in the group of multisite-social networkers: $\chi^{2}(47)=577.11, \chi^{2} / d f=12.28$, CFI $=.951$, TLI $=.932$, RMSEA $=.109,90 \%$ CI $[.101$, .117]. On the basis of modification indices residuals of the first and second item of the BSMAS, as well of the BFAS were allowed to correlate as well as the residuals of the fourth and sixth items of the BSMAS, as well in the BFAS. Further the residual of the fourth item of the BSMAS was correlated with the residual of the sixth item in the BFAS. Also, the residual of the sixth item of the BSMAS correlated with the residual of the fourth item on the BFAS. In the group of the Facebook-only users the model had a good fit: $\chi^{2}(39)=36.12$, $\chi^{2} / d f=.93, \mathrm{CFI}=1.000, \mathrm{TLI}=1.003, \mathrm{RMSEA}=.000,90 \%$ CI $[.000, .051]$. In the group of the multisite-social networkers, the model also had a good fit: $\chi^{2}(39)=97.92$, $\chi^{2} / d f=2.51, \mathrm{CFI}=.995, \mathrm{TLI}=.991, \mathrm{RMSEA}=.040,90 \%$ CI $[.030, .050]$. Standardized factor loadings of the items can be found in Fig. 2. In the group of Facebook-only users the correlation between the BFAS and the BSMAS was .94. In the group of multisite-social networkers this relationship was 
Fig. 2 The factor structure of the Bergen Social Media Addiction Scale (BSMAS) and Bergen Facebook Addiction Scale (BFAS) for group of Facebookonly users $(n=146)$ and for multisocial networkers $(n=953)$.

Standardized loadings are indicated on the arrows. All loadings are significant at $p<.001$. Results for multi-social networkers have been bolded

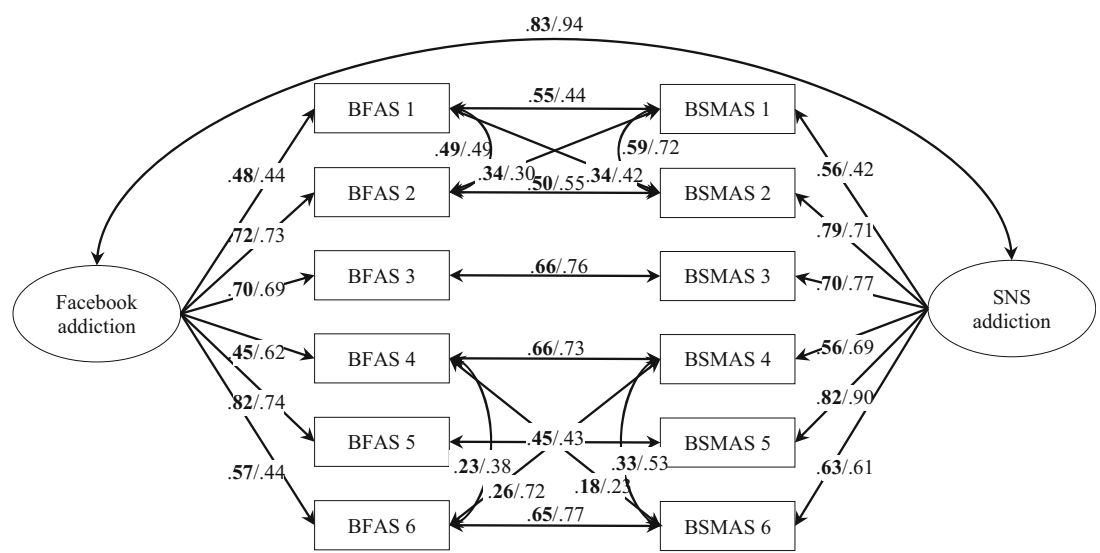

.83. This difference was statistically significant $(z=6.12$, $p<.001)$.

Table 2 presents mean scores, standard deviations, percentages, and correlation coefficients in the whole sample. In the group of the multisite-social networkers the correlations between SNS addiction and criterion variables were compared to correlations between Facebook addiction and criterion variables. A test $z$ for dependent groups was used to compare these correlation coefficients (see Table 3). According to the polythetic approach (i.e., scoring 4 [often] or 5 [very often] on at least four out of six items), the percentage of people who meet the criteria of addiction was calculated showing that approximately $8.2 \%$ (95\% $\mathrm{CI}=6.7 \%-9.9 \%$ ) of young adults were identified as SNS addicts and $4.9 \%(95 \% \mathrm{CI}=3.8 \%-6.3 \%)$ as Facebook addicts, respectively.

Regression analysis for perceived stress (see Table 4) showed that the independent variables explained a total of $26.5 \%$ of the variance, $F_{9,943}=37.79, p<.001$. Significant independent variables in Step 4 were extraversion $(\beta=-.14$, $p<.001)$, conscientiousness $(\beta=-.23, p<.001)$, emotional stability $(\beta=-.31, p<.001)$ and SNS addiction $(\beta=.14$, $p=.001)$.

Regression analysis for general subjective well-being (see Table 4) showed that the independent variables explained a total of $26.5 \%$ of the variance, $F_{9,943}=37.73, p<.001$. Significant independent variables in Step 4 were extraversion $(\beta=.32$, $p<.001)$, conscientiousness $(\beta=.23, p<.001)$, emotional stability $(\beta=.19, p<.001)$ and SNS addiction $(\beta=-.09, p=.029)$.

\section{Discussion}

\section{Validity and Reliability of the BSMAS}

The results showed that the model with one factor of SNS addiction had poor fit to the data. Previous studies suggest that such lack of acceptable fit might be related to the fact

Table 2 Mean scores and standard deviations $(S D)$, percentages, and correlation coefficients (Pearson product-moment/point-biserial) between study variables $(n=1099)$

\begin{tabular}{|c|c|c|c|c|c|c|c|c|c|c|c|}
\hline Variable & Mean $(S D) /$ Percentages & 1. & 2. & 3. & 4. & 5. & 6. & 7. & 8. & 9. & 10. \\
\hline 1. SNS addiction & $14.76(4.71)$ & - & & & & & & & & & \\
\hline 2. Facebook addiction & $12.83(4.76)$ & $.76^{* *}$ & - & & & & & & & & \\
\hline 3. Gender ${ }^{a}$ & $71.9 \%$ females & $-.23^{* *}$ & $-.18 * *$ & - & & & & & & & \\
\hline 4. Age & $21.44(2.85)$ & $-.11 * *$ & -.04 & .06 & - & & & & & & \\
\hline 5. Extraversion & $8.76(3.04)$ & $.07 *$ & .05 & $-.09 * *$ & .03 & - & & & & & \\
\hline 6. Agreeableness & $9.65(2.31)$ & -.02 & -.04 & .04 & .03 & .01 & - & & & & \\
\hline 7. Conscientiousness & $9.29(2.71)$ & $-.14 * *$ & $-.13 * *$ & $-.11 * *$ & .01 & $.11 * *$ & $.12 * *$ & - & & & \\
\hline 8. Emotional stability & $7.98(2.79)$ & $-.23 * *$ & $-.21 * *$ & $.22 * *$ & $.06^{*}$ & $.08^{*}$ & $.33^{* *}$ & $.19 * *$ & - & & \\
\hline 9. Openness to experience & $10.08(2.24)$ & -.01 & -.03 & $-.07 *$ & .03 & $.34 * *$ & $-.07 *$ & $.13^{* *}$ & $-.07 *$ & - & \\
\hline 10. Perceived stress & $11.18(3.24)$ & $.28 * *$ & $.25 * *$ & $-.12 * *$ & $-.07 *$ & $-.19 * *$ & $-.09 * *$ & $-.33 * *$ & $-.38 * *$ & $-.07 *$ & - \\
\hline 11. General subjective well-being & $33.80(8.71)$ & $-.15^{* *}$ & $-.13 * *$ & .01 & .04 & $.37 * *$ & $.15^{* *}$ & $.34 * *$ & $.29 * *$ & $.12 * *$ & $-.54 * *$ \\
\hline
\end{tabular}

${ }^{\text {a }}$ Point-biserial correlation coefficient $(0=$ female, $1=$ male $)$

$* p<.05 . * * p<.01$ 
Table 3 Correlation coefficients (Pearson product-moment/point-biserial) between study variables for multisite-social networkers $(n=953)$

\begin{tabular}{|c|c|c|c|c|c|}
\hline Variable & Mean $(S D) /$ Percentages & SNS addiction & Facebook addiction & $z$ & $p^{b}$ \\
\hline 1. Gender ${ }^{\mathrm{a}}$ & $74.2 \%$ females & $-.22 * *$ & $-.17 * *$ & -2.68 & .007 \\
\hline 2. Age & $21.25(2.41)$ & $-.10 * *$ & -.02 & -3.50 & $<.001$ \\
\hline 3. Extraversion & $8.87(3.00)$ & .06 & .05 & .44 & .596 \\
\hline 4. Agreeableness & $9.59(2.32)$ & .01 & -.01 & .87 & .290 \\
\hline 5. Conscientiousness & $9.23(2.70)$ & $-.14 * *$ & $-.13 * *$ & -.44 & .593 \\
\hline 6. Emotional stability & $7.87(2.79)$ & $-.20 * *$ & $-.19 * *$ & -.45 & .589 \\
\hline 7. Openness to experience & $10.11(2.22)$ & -.03 & -.03 & .00 & 1.000 \\
\hline 8. Stress & $11.33(3.22)$ & $.26^{* *}$ & $.23 * *$ & 1.35 & .101 \\
\hline 9. General subjective well-being & $33.53(8.72)$ & $-.14 * *$ & $-.11 * *$ & -1.32 & .110 \\
\hline
\end{tabular}

${ }^{\mathrm{a}}$ Point-biserial correlation coefficient $(0=$ female, $1=$ male $) .{ }^{\mathrm{b}}$ Critical $p$ value after Bonferroni correction is 0.006

$* p<.05 . * * p<.01$

that measures based on the core components of addiction are additionally influenced by a general component of high time and energy investment into the particular behaviour, which manifests as correlations between items residuals (Atroszko et al. 2018; Atroszko et al. 2017). Thus, correlations between two previously reported pairs of items residuals (Item 1 and Item 2 as well as Item 4 and Item 6; see Atroszko et al. 2018; Bereznowski et al. 2016; Charzyńska and Góźdź 2014; Monacis et al. 2017) were allowed. The modified model showed acceptable fit with the data. All factor loadings were significant, their standardized values were above .40 , and the scale had high internal consistency (H1 supported).

\section{Relationship Between SNS Addiction and Facebook Addiction}

The results showed that SNS addiction was strongly associated with Facebook addiction and that this relationship was stronger in the group of Facebook-only users than in the group of multisite-social networkers (H2 supported). These results support good convergent and discriminant validity of the BSMAS (H1 supported), and suggest that SNS addiction is completely equivalent to Facebook addiction among Facebook-only users (as Facebook is the only SNS these individuals use) alas not completely equivalent to Facebook addiction among multisite-social networkers (as Facebook is not the only SNS these individuals use). Therefore, the results support the notion that SNS addiction and Facebook addiction refer to the same underlying addictive process to social networking with somewhat different manifestations which could reflect level of addiction, stage of addiction or subtype of addiction. The construct of SNS addiction seems valid when researchers are interested in general aspects of SNS-functioning, which are relevant for all individuals addicted to SNSs. However, assessment of addiction to a specific SNS (e.g.
Facebook) should be conducted when researchers are interested in unique aspects of functioning, which may differ between individuals addicted to specific SNSs (Andreassen and Pallesen 2013; Ryan et al. 2014; see also Throuvala et al. 2019). However, it must be kept in mind that the large majority of SNSs users are multisite-social networkers. Therefore, differentiating by SNSs use might not be the most costeffective and informative strategy to collect data on addiction (Griffiths 2012; Kuss and Griffiths 2017). A more fruitful approach might be an investigation of SNS addiction along with individuals' motives to use SNSs and activities in which individuals engage in on the SNSs (Andreassen and Pallesen 2013; Griffiths et al. 2014; Kuss and Griffiths 2017; Ryan et al. 2014; see also Throuvala et al. 2019).

\section{SNS Addiction and Personality}

Congruently with previous studies, the results showed that SNS addiction was inversely associated with conscientiousness and emotional stability (H3 supported; De Cock et al. 2014; Marino et al. 2018a). Additionally, SNS addiction was positively associated with extraversion but unrelated to agreeableness and openness to experience. It should be noted, that an in-depth investigation of these relationships requires application of multivariate analyses rather than the analysis of zeroorder correlations. For example, currently the data suggests that while zero-order correlations between Facebook addiction and extraversion are either non-significant or negative (Marino et al. 2018a), the more complementary regression models controlling for wide range of personality factors show a positive relationship between them (see Andreassen et al. 2013; Atroszko et al. 2018), which could be potentially explained by the shared covariance between extraversion, neuroticism and Facebook addiction. However, future studies should investigate potential moderating effects of other variables (e.g., culture or patterns of use of SNSs [e.g., active vs. 
Table 4 Results of hierarchical multiple regression analyses in which SNS addiction, Facebook addiction, age, gender and big five personality traits were regressed upon the scores on perceived stress and subjective well-being for multisite-social networkers $(n=953)$

\begin{tabular}{lllll}
\hline & \multicolumn{2}{l}{ Perceived stress } & & \multicolumn{2}{l}{ General subjective well-being } \\
\cline { 2 - 3 } & $\beta$ & $\Delta R^{2}$ & $\beta$ & $\Delta R^{2}$ \\
\hline
\end{tabular}

Step 1

$.052 * *$

Facebook addiction

Step 2

$\begin{array}{lc}\text { Facebook addiction } & .22 * * \\ \text { Gender }^{\mathrm{a}} & -.07 * \\ \text { Age } & -.04\end{array}$

Step 3

$\begin{array}{lc} & \\ \text { Facebook addiction } & .14^{* *} \\ \text { Gender } & -.05 \\ \text { Age } & -.03 \\ \text { Extraversion } & -.13^{* *} \\ \text { Agreeableness } & .06 \\ \text { Conscientiousness } & -.24^{* *} \\ \text { Emotional stability } & -.31^{* *} \\ \text { Openness to experience } & -.01\end{array}$

Step 4

Facebook addiction
Gender $^{\mathrm{a}}$
Age
Extraversion
Agreeableness
Conscientiousness
Emotional stability
Openness to experience
SNS addiction
Total $R^{2}$

$$
.23 * *
$$

.04

$-.04$

$-.02$

$-.14 * *$

.05

$-.23 * *$

$-.31 * *$

$-.01$

$.14 * *$
$.012 * *$

$-.11$

$.006^{*}$

.001

$-.11 * *$

$-.02$

$-.01$

$.198 * *$

$.248 * *$

$-.06$

.00

$-.00$

$.31 * *$

.05

$.24 * *$

$.19 * *$

.01

$.008^{* *}$

$.004 *$

${ }^{\mathrm{a}} 0=$ female, $1=$ male

$* p<.05 . * * p<.01$

passive]) on the relationships between SNS addiction and personality traits (see also Marino et al. 2018a).

\section{SNS Addiction, Facebook Addiction, and their Relationships with Criterion Variables in Group of Multisite-Social Networkers}

SNS addiction and Facebook addiction differed in strengths of their relationships with gender and age (in both cases the relationship with SNS addiction was stronger). On the other hand, there were no differences in strengths of their relationships with personality traits, perceived stress, and general subjective wellbeing. However, it is worth noting that although the differences were not statistically significant, the relationships with SNS addiction were stronger than the relationships with Facebook addiction in cases of almost all criterion variables. These results show there were some minor differences in strengths of relationships of SNS addiction and Facebook addiction with the criteria variables; however, the differences were by and large marginal (H5 supported). Consequently, it suggests that, with 
adequate caution, studies of correlates of SNS addiction and Facebook addiction can be perceived as complementary (e.g. studies on correlates of Facebook addiction seem to converge with studies on correlates of SNS addiction and vice versa). Therefore, future studies on correlates of SNS addiction and Facebook addiction may be assumed to produce similar results, indicating the presence of generic antecedents and consequences. It should however be noted that this assumption might be limited to the present study's variables and sample.

\section{SNS Addiction, Facebook Addiction, Perceived Stress, and General Subjective Well-Being}

The results showed that SNS addiction was positively associated with perceived stress and negatively associated with general subjective well-being even after controlling for Facebook addiction and other studied variables, which is congruent with previous studies (H4 and H6 substantiated; Hou et al. 2017; Marino et al. 2018b; Pontes 2017; Tromholt 2016; Turel et al. 2018; Xue et al. 2018). Facebook addiction showed a similar relationship with these variables before controlling for SNS addiction. These results suggest that there is a disproportion in the unique contribution of SNS addiction and Facebook addiction to the impaired functioning of individuals. Possibly, such disproportion is a result of differences in the specificity between SNS addiction and Facebook addiction (see Griffiths 2012). The former is a broader construct, which overlaps with the latter as well as include other addictions to particular SNSs (e.g. Instagram, Snapchat, Twitter; Kuss and Griffiths 2017). As a result, all of the impairment related to Facebook addiction are also present in SNS addiction, while SNS addiction seems to be associated with additional impairment. Hence, these results complement a picture of the relationship between SNS addiction and Facebook addiction.

\section{Strengths and Limitations}

To the best of our knowledge this is the first empirical study investigating the relationship between SNS addiction and Facebook addiction, being a subject of heated theoretical discussion during the recent years (see Andreassen and Pallesen 2013; Griffiths 2012; Griffiths et al. 2014; Kuss and Griffiths 2017). Moreover, the present study also sheds light on methodological and theoretical challenges related to the high number of multisitesocial networkers among users of SNSs. It comprised a relatively large sample size (providing high statistical power) as well as use of valid and reliable psychometric tools. Consequently, it significantly adds to the existing literature on behavioral addictions and provide valuable insights into the nature of the relationship between SNS addiction and Facebook addiction.

In terms of limitations, the sample size of Facebook-only users was relatively small (although quite well representing proportions in population of SNSs users; GlobalWebIndex
2017) which reduced statistical power regarding the comparison between Facebook-only users and multisite-social networkers. Moreover, all data were self-reported and a cross-sectional design was used, rendering the data vulnerable to limitations associated with such data (e.g., common method, social desirability and recall biases). The sample was not representative of the general population of SNS users and mainly comprised students, which puts restrictions on the generalizability to other populations.

\section{Conclusions and Future Studies Directions}

The present study showed that SNS addiction can be validly and reliably measured among young adults in Poland. What is more, it provided empirical data about the relationship between SNS addiction and Facebook addiction, which appear to be reflecting common addictive process to social networking with somewhat specific manifestations. Nevertheless, SNS addiction seems to be a more suitable construct to study in most cases, firstly because the large majority of SNSs users are multisite-social networkers (GlobalWebIndex 2017). Thus, in many cases it is difficult to apply methodological and statistical procedures which would allow to study differences between addictions to particular SNSs (and in some cases it might not be even possible). Secondly, a more generic assessment approach seems preferable because other variables related to usage of SNSs (e.g. motives to use SNSs, activities in which users engage on SNSs, patterns of use of SNSs [e.g. active vs. passive]) seems to be more important to identify than to study correlates of particular SNS (Andreassen and Pallesen 2013; Griffiths et al. 2014; Kuss and Griffiths 2017; Ryan et al. 2014; see also Throuvala et al. 2019). Thirdly, a more generic assessment in terms of predictors and consequences seems to correspond well to the findings obtained when assessing addiction to more specific SNS. However, Facebook addiction and other addictions to particular SNSs might still be useful constructs, for example they might be used to determine which of addictions to particular SNS are the biggest contributors to the individuals' harm (e.g. deteriorated well-being) or which of addictions to particular SNS are the biggest contributors to general SNS addiction. Consequently, such studies could lead to successful therapeutic interventions focusing on the most harmful SNSs.

Future studies should further investigate the relationship between SNS addiction and Facebook addiction (e.g. measurement invariance between BSMAS and BFAS, as well as multi-group analysis to compare the group of Facebook-only users and the group of multisite-social networkers). Such investigations should consider using purposive sampling in order to maximize the number of Facebook-only users participating, and thus the relevant statistical power. Future studies should also investigate the relationships between SNS addiction and other addictions to particular SNSs (e.g. Instagram, Snapchat, Twitter) as well as the 
relationships between different addictions to particular SNSs (e.g. Facebook vs. Instagram). Moreover, we suggest implementing question about SNSs used by participants as a standard procedure in future studies as it appears that differentiation between multisite-social networkers and users of a single SNS (e.g. Facebook-only users) might be essential to facilitate advancement in this field. Future studies should also investigate the potential role of motives to use SNSs, activities in which users engage on SNSs, and patterns of use of SNSs (e.g. active vs. passive) in terms of SNS addiction. Last but not least, future studies should also include further investigation of addictive properties of SNS addictions as well as harm and distress caused by specific and generic SNS addictions.

Authors' Contribution All authors contributed to the study conception and design. Material preparation, data collection and analysis were performed by [Julia Maria Balcerowska], [Adriana Biernatowska] and [Piotr Bereznowski]. The first draft of the manuscript was written by [Julia Maria Balcerowska], [Adriana Biernatowska] and [Piotr Bereznowski] and all authors commented on previous versions of the manuscript. All authors read and approved the final manuscript.

Conceptualization: [Julia Maria Balcerowska], [Piotr Bereznowski]; Methodology: [Julia Maria Balcerowska], [Piotr Bereznowski], [Adriana Biernatowska]; Formal analysis and investigation: [Julia Maria Balcerowska], [Piotr Bereznowski], [Adriana Biernatowska]; Writing original draft preparation: [Julia Maria Balcerowska], [Piotr
Bereznowski], [Adriana Biernatowska]; Writing - review and editing: [Paweł Andrzej Atroszko], [Ståle Pallesen], [Cecilie Schou Andreassen].

Data Availability The datasets generated during and/or analyzed during the current study are available from the corresponding author on reasonable request.

\section{Compliance with Ethical Standards}

Informed Consent Informed consent was obtained from all individual participants included in the study. All gathered data was anonymous, and participants were informed about all the proper details about the study and their role in it, including that they can withdraw at any point. Attaining formal and written informed consent was not regarded as necessary as voluntary completion of the questionnaires was regarded as providing consent, and no medical information was gathered.

Ethical Approval All procedures performed in studies involving human participants were in accordance with the ethical standards of the institutional and/or national research committee (Ethics Committee for Research Projects at the Institute of Psychology, University of Gdańsk; reference number: 15/2019) and with the 1964 Helsinki declaration and its later amendments or comparable ethical standards.

Disclosure of Potential Conflicts of Interest The authors declare that they have no conflict of interest.

\section{APPENDIX}

Bergen Social Media Addiction Scale

Instruction: Below you find some questions about your relationship to and use of social networking sites (Facebook, Twitter, Instagram and the like). Choose the response alternative for each question that best describes you.

How often during the last year have you...

[Instrukcja: Poniżej znajduje się kilka pytań dotyczących myśli, zachowań i odczuć dotyczących portali społecznościowych (Facebook, Twitter, Instagram itp.).

Prosimy, abyś dla każdego pytania zaznaczył(-a), jak często w ciągu ostatniego roku...]

\begin{tabular}{|c|c|c|}
\hline Item & Addiction component & Wording \\
\hline \multirow[t]{2}{*}{ BSMAS1 } & Salience & spent a lot of time thinking about social networking sites or planned use of social media? \\
\hline & & [myślałeś(aś) o portalach społecznościowych lub planowałeś(aś) ich używanie?] \\
\hline \multirow[t]{2}{*}{ BSMAS2 } & Tolerance & felt an urge to use social networking sites more and more? \\
\hline & & [odczuwałeś(aś) rosnącą potrzebę korzystania z portali społecznościowych?] \\
\hline \multirow[t]{2}{*}{ BSMAS3 } & Mood modification & used social networking sites in order to forget about personal problems? \\
\hline & & [używałeś(aś) portali społecznościowych, żeby zapomnieć o problemach osobistych?] \\
\hline \multirow[t]{2}{*}{ BSMAS4 } & Relapse & tried to cut down on the use of social networking sites without success? \\
\hline & & [próbowałeś(aś) bezskutecznie ograniczyć używanie portali społecznościowych?] \\
\hline \multirow[t]{2}{*}{ BSMAS5 } & Withdrawal & become restless or troubled if you have been prohibited from using social networking sites? \\
\hline & & [byłeś(aś) niespokojny(a) lub zmartwiony(a), jeśli nie mogłeś(aś) używać portali społecznościowych?] \\
\hline \multirow[t]{2}{*}{ BSMAS6 } & Conflict & used social networking sites so much that it has had a negative impact on your job/studies? \\
\hline & & ywałeś(aś) portali społecznościowych tak dużo, że \\
\hline
\end{tabular}

Response options were: (1) very rarely, (2) rarely, (3) sometimes, (4) often, (5) very often.

[] Includes Polish translation of Bergen Social Media Addiction Scale.

Scoring: Add the scores of the items for the total score. 
Open Access This article is licensed under a Creative Commons Attribution 4.0 International License, which permits use, sharing, adaptation, distribution and reproduction in any medium or format, as long as you give appropriate credit to the original author(s) and the source, provide a link to the Creative Commons licence, and indicate if changes were made. The images or other third party material in this article are included in the article's Creative Commons licence, unless indicated otherwise in a credit line to the material. If material is not included in the article's Creative Commons licence and your intended use is not permitted by statutory regulation or exceeds the permitted use, you will need to obtain permission directly from the copyright holder. To view a copy of this licence, visit http://creativecommons.org/licenses/by/4.0/.

\section{References}

Andreassen, C. S. (2015). Online social network site addiction: A comprehensive review. Current Addiction Reports. https://doi.org/10. 1007/s40429-015-0056-9.

Andreassen, C. S., \& Pallesen, S. (2013). Facebook addiction: A reply to Griffiths (2012). Psychological Reports. https://doi.org/10.2466/02. 09.PR0.113x32z6.

Andreassen, C. S., \& Pallesen, S. (2014). Social network site addictionAn overview. Current Pharmaceutical Design, 20(25), 4053-4061.

Andreassen, C. S., Torsheim, T., Brunborg, G. S., \& Pallesen, S. (2012). Development of a Facebook addiction scale. Psychological Reports. https://doi.org/10.2466/02.09.18.PR0.110.2.501-517.

Andreassen, C. S., Griffiths, M. D., Gjertsen, S. R., Krossbakken, E., Kvam, S., \& Pallesen, S. (2013). The relationships between behavioral addictions and the five-factor model of personality. Journal of Behavioral Addictions. https://doi.org/10.1556/JBA.2.2013.003.

Andreassen, C. S., Billieux, J., Griffiths, M. D., Kuss, D. J., Demetrovics, Z., Mazzoni, E., \& Pallesen, S. (2016). The relationship between addictive use of social media and video games and symptoms of psychiatric disorders: A large-scale cross-sectional study. Psychology of Addictive Behaviors. https://doi.org/10.1037/ adb0000160.

Andreassen, C. S., Pallesen, S., \& Griffiths, M. D. (2017). The relationship between addictive use of social media, narcissism, and selfesteem: Findings from a large national survey. Addictive Behaviors. https://doi.org/10.1016/j.addbeh.2016.03.006.

Atroszko, P. A. (2015). The structure of study addiction: Selected risk factors and the relationship with stress, stress coping and psychosocial functioning (Unpublished doctoral disseration). University of Gdansk, Poland.

Atroszko, P. A., Andreassen, C. S., Griffiths, M. D., \& Pallesen, S. (2015). Study addiction- A new area of psychological study: Conceptualization, assessment, and preliminary empirical findings. Journal of Behavioral Addictions. https://doi.org/10.1556/2006.4.2015.007.

Atroszko, P. A., Andreassen, C. S., Griffiths, M. D., \& Pallesen, S. (2016a). Study addiction: A cross-cultural longitudinal study examining temporal stability and predictors of its changes. Journal of Behavioral Addictions. https://doi.org/10.1556/2006.5.2016.024.

Atroszko, P. A., Andreassen, C. S., Griffiths, M. D., \& Pallesen, S. (2016b). The relationship between study addiction and work addiction: A cross-cultural longitudinal study. Journal of Behavioral Addictions. https://doi.org/10.1556/2006.5.2016.076.

Atroszko, P. A., Pallesen, S., Griffiths, M. D., \& Andreassen, C. S. (2017). Work addiction in Poland: Adaptation of the Bergen Work Addiction Scale and relationship with psychopathology. Health Psychology Report. https://doi.org/10.5114/hpr.2017.68759.

Atroszko, P. A., Balcerowska, J. M., Bereznowski, P., Biernatowska, A., Pallesen, S., \& Andreassen, C. S. (2018). Facebook addiction among polish undergraduate students: Validity of measurement and relationship with personality and well-being. Computers in Human Behavior. https://doi.org/10.1016/j.chb.2018.04.001.

Atroszko, P. A., Sawicki, A. J., \& Atroszko, B. (2019). Ultra-short protocol for measuring subjective well-being based on single-item measures. Manuscript in preparation.

Bányai, F., Zsila, Á., Király, O., Maraz, A., Elekes, Z., Griffiths, M. D., et al. (2017). Problematic social media use: Results from a largescale nationally representative adolescent sample. PLoS One. https:// doi.org/10.1371/journal.pone.0169839.

Bereznowski, P., Balcerowska, J. M., \& Biernatowska, A. (2016). Walidacja skali uzależnienia od Facebooka (the Bergen Facebook Addiction Scale) autorstwa Andreassen, Torsheima, Brunborga $i$ Pallesen wśród polskich uczniów i studentów. Paper presented at Studencka Konferencja Naukowa Psych-On, Łódź, Poland.

Błachnio, A., Przepiorka, A., Senol-Durak, E., Durak, M., \& Sherstyuk, L. (2017). The role of personality traits in Facebook and internet addictions: A study on polish, Turkish, and Ukrainian samples. Computers in Human Behavior. https://doi.org/10.1016/j.chb. 2016.11.037.

Brand, M., Young, K. S., \& Laier, C. (2014). Prefrontal control and internet addiction: A theoretical model and review of neuropsychological and neuroimaging findings. Frontiers in Human Neuroscience. https://doi.org/10.3389/fnhum.2014.00375.

Caplan, S. E. (2010). Theory and measurement of generalized problematic internet use: A two-step approach. Computers in Human Behavior. https://doi.org/10.1016/j.chb.2010.03.012.

Charzyńska, E., \& Góźdź, J. (2014). W sieci uzależnienia. Polska adaptacja skali uzależnienia od Facebooka (the Bergen Facebook Addiction Scale) C. S. Andreassen, T. Torsheima, G. S. Brunborga i S. Pallesen [The social media trap. Polish adaptation of the Bergen Facebook Addiction Scale C.S. Andreassen, T. Torsheim, G.S. Brunborg and S. Pallesen]. Chowanna, 22, 163-185.

Chen, I. H., Strong, C., Lin, Y. C., Tsai, M. C., Leung, H., Lin, C. Y., et al. (2020). Time invariance of three ultra-brief internet-related instruments: Smartphone Application-Based Addiction Scale (SABAS), Bergen social media addiction scale (BSMAS), and the nine-item internet gaming disorder scale-short form (IGDS-SF9)(study part B). Addictive Behaviors. https://doi.org/10.1016/j.addbeh.2019.04. 018.

Cohen, S., Kamarck, T., \& Mermelstein, R. (1983). A global measure of perceived stress. Journal of Health and Social Behavior. https://doi. org/10.2307/2136404.

Davis, R. A. (2001). A cognitive-behavioral model of pathological internet use. Computers in Human Behavior. https://doi.org/10.1016/ S0747-5632(00)00041-8.

De Cock, R., Vangeel, J., Klein, A., Minotte, P., Rosas, O., \& Meerkerk, G.-J. (2014). Compulsive use of social networking sites in Belgium: Prevalence, profile, and the role of attitude toward work and school. Cyberpsychology, Behavior, and Social Networking. https://doi.org/ 10.1089/cyber.2013.0029.

Elphinston, R. A., \& Noller, P. (2011). Time to face it! Facebook intrusion and the implications for romantic jealousy and relationship satisfaction. Cyberpsychology, Behavior and Social Networking. https://doi. org/10.1089/cyber.2010.0318.

Facebook. (2019). Facebook Reports Fourth Quarter and Full Year 2018 Results. Resource document. Facebook website. https://investor.fb. com/investor-news/press-release-details/2019/Facebook-ReportsFourth-Quarter-and-Full-Year-2018Results/default.aspx. Accessed 30 Jan 2019.

Fan, W., \& Yan, Z. (2010). Factors affecting response rates of the web survey: A systematic review. Computers in Human Behavior. https://doi.org/10.1016/j.chb.2009.10.015.

GlobalWebIndex. (2017). Social media engagement. Examining how internet users interact and engage with social media. Resource 
document. Global Web Index website. https://pro.globalwebindex. net/reports/17988. Accessed 25 Feb 2019.

GlobalWebIndex (2018). Social. GlobalWebIndex's flagship report on the latest trends in social media. Resource document. Global Web Index website. https://pro.globalwebindex.net/reports/18048. Accessed 15 Mar 2019.

Gosling, S. D., Rentfrow, P. J., \& Swann Jr., W. B. (2003). A very brief measure of the big-five personality domains. Journal of Research in Personality. https://doi.org/10.1016/S0092-6566(03)00046-1.

Grant, J. E., Potenza, M. N., Weinstein, A., \& Gorelick, D. A. (2010), Introduction to behavioral addictions. The American Journal of Drugs and Alcohol Abuse. https://doi.org/10.3109/00952990.2010. 491884.

Griffiths, M. (2005). A "components" model of addiction within a biopsychosocial framework. Journal of Substance Use. https://doi. org/10.1080/14659890500114359.

Griffiths, M. D. (2012). Facebook addiction: Concerns, criticism, and recommendations-A response to Andreassen and colleagues. Psychological Reports. https://doi.org/10.2466/01.07.18.PR0.110. 2.518-520.

Griffiths, M. D., Kuss, D. J., \& Demetrovics, Z. (2014). Social networking addiction: An overview of preliminary findings. In K. P. Rosenberg \& L. C. Feder (Eds.), Behavioral addictions: Criteria, evidence, and treatment (pp. 119-141). London: Academic Press.

He, Q., Turel, O., \& Bechara, A. (2017). Brain anatomy alterations associated with social networking site (SNS) addiction. Scientific Reports, 7, 1-8. https://doi.org/10.1038/srep45064.

Hormes, J. M., Kearns, B., \& Timko, C. A. (2014). Craving Facebook? Behavioral addiction to online social networking and its association with emotion regulation deficits. Addiction. https://doi.org/10.1111/ add. 12713

Hou, X.-L., Wang, H.-Z., Guo, C., Gaskin, J., Rost, D. H., \& Wang, J. L. (2017). Psychological resilience can help combat the effect of stress on problematic social networking site usage. Personality and Individual Differences. https://doi.org/10.1016/j.paid.2016.12.048.

Hu, L., \& Bentler, P. M. (1999). Cutoff criteria for fit indexes in covariance structure analysis: Conventional criteria versus new alternatives. Structural Equation Modeling: A Multidisciplinary Journal. https://doi.org/10.1080/10705519909540118.

Katz, E., Haas, H., \& Gurevitch, M. (1973). On the use of the mass media for important things. American Sociological Review. https://doi.org/ $10.2307 / 2094393$.

Kircaburun, K., \& Griffiths, M. D. (2018). Instagram addiction and the big five of personality: The mediating role of self-liking. Journal of Behavioral Addictions. https://doi.org/10.1556/2006.7.2018.15.

Kuss, D. J., \& Griffiths, M. D. (2011). Online social networking and addiction-A review of the psychological literature. International Journal of Environmental Research and Public Health. https://doi. org/10.3390/ijerph8093528.

Kuss, D. J., \& Griffiths, M. D. (2017). Social networking sites and addiction: Ten lessons learned. International Journal of Environmental Research and Public Health. https://doi.org/10.3390/ ijerph14030311.

Leung, H., Pakpour, A. H., Strong, C., Lin, Y. C., Tsai, M. C., Griffiths, M. D., et al. (2020). Measurement invariance across young adults from Hong Kong and Taiwan among three internet-related addiction scales: Bergen social media addiction scale (BSMAS), smartphone application-based addiction scale (SABAS), and internet gaming disorder scale-short form (IGDS-SF9)(study part A). Addictive Behaviors. https://doi.org/10.1016/j.addbeh.2019.04.027.

Lin, C. Y., Broström, A., Nilsen, P., Griffiths, M. D., \& Pakpour, A. H. (2017). Psychometric validation of the Persian Bergen social media addiction scale using classic test theory and Rasch models. Journal of Behavioral Addictions. https://doi. org/10.1556/2006.6.2017.071.
Marino, C., Gini, G., Vieno, A., \& Spada, M. M. (2018a). A comprehensive meta-analysis on problematic Facebook use. Computers in Human Behavior. https://doi.org/10.1016/j.chb.2018.02.009.

Marino, C., Gini, G., Vieno, A., \& Spada, M. M. (2018b). The associations between problematic Facebook use, psychological distress and well-being among adolescents and young adults: A systematic review and meta-analysis. Journal of Affective Disorders. https://doi. org/10.1016/j.jad.2017.10.007.

Monacis, L., de Palo, V., Griffiths, M. D., \& Sinatra, M. (2017). Social networking addiction, attachment style, and validation of the Italian version of the Bergen social media addiction scale. Journal of Behavioral Addictions. https://doi.org/10.1556/2006.6.2017.023.

Montag, C., Bey, K., Sha, P., Li, M., Chen, Y.-F., Liu, W.-Y., et al. (2014). Is it meaningful to distinguish between generalized and specific internet addiction? Evidence from a cross-cultural study from Germany, Sweden, Taiwan and China. Asia-Pacific Psychiatry. https://doi.org/10.1111/appy.12122.

Müller, K. W., Dreier, M., Beutel, M. E., Duven, E., Giralt, S., \& Wölfling, K. (2016). A hidden type of internet addiction? Intense and addictive use of social networking sites in adolescents. Computers in Human Behavior. https://doi.org/10.1016/j.chb. 2015.09.007

Muthén, L. K., \& Muthén, B. O. (1998-2010). Mplus User's Guide (6th ed.). Los Angeles: Muthén \& Muthén.

Ndasauka, Y., Hou, J., Wang, Y., Yang, L., Yang, Z., Ye, Z., et al. (2016). Excessive use of twitter among college students in the UK: Validation of the Microblog Excessive Use Scale and relationship to social interaction and loneliness. Computers in Human Behavior. https://doi.org/10.1016/j.chb.2015.10.020.

Pelling, E. L., \& White, K. M. (2009). The theory of planned behavior applied to young people's use of social networking web sites. Cyberpsychology \& Behavior. https://doi.org/10.1089/cpb.2009. 0109.

Phanasathit, M., Manwong, M., Hanprathet, N., Khumsri, J., \& Yingyeun, R. (2015). Validation of the Thai version of Bergen Facebook Addiction Scale (Thai-BFAS). Journal of the Medical Association of Thailand, 98(S2), 108-117.

Pontes, H. M. (2017). Investigating the differential effects of social networking site addiction and internet gaming disorder on psychological health. Journal of Behavioral Addictions. https://doi.org/10. 1556/2006.6.2017.075.

Pontes, H. M., Andreassen, C. S., \& Griffiths, M. D. (2016). Portuguese validation of the Bergen Facebook addiction scale: An empirical study. International Journal of Mental Health and Addiction, 14, 1062-1073. https://doi.org/10.1007/s11469-016-9694-y.

Punyanunt-Carter, N. M., De La Cruz, J. J., \& Wrench, J. S. (2017). Investigating the relationships among college students' satisfaction, addiction, needs, communication apprehension, motives, and uses \& gratifications with Snapchat. Computers in Human Behavior. https://doi.org/10.1016/j.chb.2017.06.034.

Ryan, T., Chester, A., Reece, J., \& Xenos, S. (2014). The uses and abuses of Facebook: A review of Facebook addiction. Journal of Behavioral Addictions. https://doi.org/10.1556/JBA.3.2014.016.

Schreiber, J. B., Nora, A., Stage, F. K., Barlow, E. A., \& King, J. (2006). Reporting structural equation modeling and confirmatory factor analysis results: A review. The Journal of Educational Research. https://doi.org/10.3200/JOER.99.6.323-338.

Silva, H. R. S., Areco, K. C. N., Bandiera-Paiva, P., Galvão, P. V. M., Garcia, A. N. M., \& Silveira, D. X. (2018). Factorial and construct validity of Portuguese version (Brazil) Bergen Facebook addiction scale. Jornal Brasileiro de Psiquiatria. https://doi.org/10.1590/ 0047-2085000000193.

Skevington, S., M., Lotfy, M., \& O'Connell, KA. (2004). The World Health Organization's WHOQOL-BREF quality of life assessment: Psychometric properties and results of the international field trial. A 
report from the WHOQOL group. Quality of Life Research, 13(2), 299-310.

Statista. (2019). Number of social network users worldwide from 2010 to 2021 (in billions). Resource document. Statista website: https:// www.statista.com/statistics/278414/number-of-worldwide-socialnetwork-users/. Accessed 25 May 2019.

Tang, C. S.-k., \& Koh, Y. Y. W. (2017). Online social networking addiction among college students in Singapore: Comorbidity with behavioral addiction and affective disorder. Asian Journal of Psychiatry. https://doi.org/10.1016/j.ajp.2016.10.027.

Throuvala, M. A., Griffiths, M. D., Rennoldson, M., \& Kuss, D. J. (2019). Motivational processes and dysfunctional mechanisms of social media use among adolescents: A qualitative focus group study. Computers in Human Behavior. https://doi.org/10.1016/j. chb.2018.12.012.

Tromholt, M. (2016). The Facebook experiment: Quitting Facebook leads to higher levels of well-being. Cyberpsychology, Behavior and Social Networking. https://doi.org/10.1089/cyber.2016.0259.

Turel, O., \& Serenko, A. (2012). The benefits and dangers of enjoyment with social networking websites. European Journal of Information Systems. https://doi.org/10.1057/ejis.2012.1.

Turel, O., Cavagnaro, D. R., \& Meshi, D. (2018). Short abstinence from online social networking sites reduces perceived stress, especially in excessive users. Psychiatry Research. https://doi.org/10.1016/j. psychres.2018.11.017.

van Rooij, A. J., Ferguson, C. J., van de Mheen, D., \& Schoenmakers, T. M. (2017). Time to abandon internet addiction? Predicting problematic internet, game, and social media use from psychosocial wellbeing and application use. Clinical Neuropsychiatry, 14(1), 113121.

Wang, C.-W., Ho, R. T. H., Chan, C. L. W., \& Tse, S. (2015). Exploring personality characteristics of Chinese adolescents with internet- related addictive behaviors: Trait differences for gaming addiction and social networking addiction. Addictive Behaviors. https://doi org/10.1016/j.addbeh.2014.10.039.

Wang, P., Wang, X., Wu, Y., Xie, X., Wang, X., Zhao, F., et al. (2018). Social networking sites addiction and adolescent depression: A moderated mediation model of rumination and self-esteem. Personality and Individual Differences. https://doi.org/10.1016/j. paid.2018.02.008.

Wiggins, J. S. (1996). The five-factor model of personality: Theoretical perspectives. New York: Guilford Press.

Wolniczak, I., Cáceres-DelAguila, J. A., Palma-Ardiles, G., Arroyo, K. J., Solís-Visscher, R., Paredes-Yauri, S., et al. (2013). Association between Facebook dependence and poor sleep quality: A study in a sample of undergraduate students in Peru. PLoS One. https://doi.org/ 10.1371/journal.pone.0059087.

Wu, A. M., Cheung, V. I., Ku, L., \& Hung, E. P. (2013). Psychological risk factors of addiction to social networking sites among Chinese smartphone users. Journal of Behavioral Addictions. https://doi.org/ 10.1556/JBA.2.2013.006.

Xue, Y., Dong, Y., Luo, M., Mo, D., Dong, W., Zhang, Z., \& Liang, H. (2018). Investigating the impact of mobile SNS addiction on individual's self-rated health. Internet Research. https://doi.org/10.1108/ IntR-05-2017-0198.

Young, K. (2009). Internet addiction: Diagnosis and treatment consideration. Journal of Contemporary Psychotherapy. https://doi.org/10. 1007/s10879-009-9120-x.

Publisher's Note Springer Nature remains neutral with regard to jurisdictional claims in published maps and institutional affiliations. 